\title{
Military Healthcare Facility
}

National Cancer Institute

\section{Source}

National Cancer Institute. Military Healthcare Facility. NCI Thesaurus. Code C114865.

A healthcare facility that provides routine therapeutic or preventive services on a military installation or one that is off base but is operated under the authority or direction of the Department of Defense or the Department of Homeland Security. 